\title{
Immunohistochemical study of PAX5 expression in lymphoid neoplasms
}

\author{
Wael Abd El Fattah Mohamed Ibrahim Nassar*(iD, Ahmed Mohamed Yehia El Hennawy, Samia Mohamed Ahmed Gabal(D),
} Mona Salah El-Din Abd El-Magid (i)

Department of Pathology, Faculty of Medicine, Cairo University, Giza, Egypt

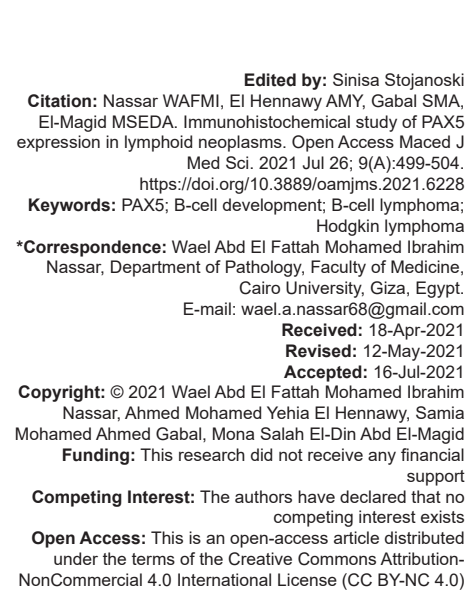

\section{Introduction}

Lymphoid neoplasms are clonal tumors of mature and immature B-cells, T-cells, or natural killer (NK)-cells at various stages of differentiation which appear to recapitulate stages of normal B-cell or T-cell differentiation. The current $\mathrm{WHO}$ classification of lymphoid neoplasms classified lymphoid neoplasms into precursor lymphoid neoplasms, mature B-cell neoplasms, mature T- and NK-cell neoplasms, and Hodgkin lymphoma [1].

Diagnosing the type of lymphoma and subcategorizing them is challenging as most of them have an overlapping morphology. Immunohistochemistry is mandatory to establish the cell lineage and PAX5 is one such marker used in diagnosis of specific subtype of lymphoma [2].

Lymphoid cells originate from hematopoietic stem cells which first differentiate to multipotent progenitors which give rise to common myeloid progenitors and common lymphoid progenitors (CLPs). CLPs differentiate through pre-pro-B-cell stage to pro-B cells, which undergo B-lineage commitment and develop to mature B-cells [3].

B-cell commitment depends on the sequential activity of the instructive transcription factors helixloop-helix protein E2A, early B-cell factor (EBF1), and PAX5 during development of CLPs to pro-B cells [4]. The E2A and EBF1 specify B-cell lineage by activating expression of B-lymphoid genes in pre-pro-B cells [5].

PAX5 is a transcription factor encoded by PAX5 gene a member of the paired box gene family located in chromosome 9p13. It encodes the transcription factor, PAX5, also known as B-cell-specific activator protein (BSAP). PAX5 acts downstream of E2A and EBF1 in the genetic hierarchy of early B-cell development, so PAX5 subsequently controls B-cell commitment at the transition to the pro-B-cell stage by repressing B-lineageinappropriate genes to suppress alternative lineage fates at B-cell commitment and by simultaneously activating B-cell-specific genes to promote B-cell development [6]. 
PAX5 also functions as an epigenetic regulator to control the chromatin state of its target genes by inducing active chromatin marks (H3K4 methylation and H3K9 acetylation) at regulatory elements of most PAX5-activated genes [7]. Conversely, PAX5 is responsible for eliminating active histone modifications at PAX5-repressed target genes [8]

PAX5 plays an essential function in regulating VH-DJH recombination at the immunoglobulin heavy chain (Igh) locus PAX5 eliminates the "repressive H3K9 dimethylation mark" from VH genes in pro-B cells [9]. PAX5 plays a critical role in controlling the contraction of the Igh locus in committed pro-B cells, which juxtaposes distal $\mathrm{VH}$ genes next to proximal $\mathrm{DH}$ segments to facilitate $\mathrm{VH}-\mathrm{DJH}$ rearrangements [10].

The physiological loss of PAX5 during terminal B-cell differentiation contributes to the initiation of plasma cell transcription program [11].

\section{Materials and Methods}

\section{Retrieval of cases}

The study included 60 cases of lymphomas. The material of the study was collected as formalin fixed, paraffin-embedded tissue blocks from archives of pathology department, Kasr EL-Ainy Faculty of medicine, Cairo University, in the period from March 2018 through April 2020.

The data collected from the pathology reports of these cases included age at time of diagnosis, sex, available clinical data (such as localized or generalized lymphadenopathy, or extranodal lesions), histopathologic diagnosis, and immunophenotyping of the cases.

\section{Inclusion criteria}

Properly fixed specimens with available blocks were included in the study.

\section{Exclusion criteria}

Improperly fixed specimens were excluded from the study.

\section{Histopathological examination}

Each paraffin block was recut by rotatory microtome at $4 \mu \mathrm{m}$ thickness then mounted on glass slides and stained by hematoxylin and eosin ( $\mathrm{H}$ and $\mathrm{E})$ for routine histopathological examination and on charged slides for immunostaining.

The immunohistochemical panel of the studied cases was obtained and reexamined from the tumor markers unit of the pathology department, Kasr EL-Ainy Faculty of Medicine, Cairo University. It included CD3, CD 5, CD20, CD10, BCL6, BCL2, CD23, CD15, CD30, Cyclin D1, and MUM1.

The diagnosis was done according to the latest WHO classification of tumors of lymphoid tissues [12].

\section{PAX 5 immunohistochemical staining}

Immunostaining was done automated using BenchMark XT (Ventana) autostainer. The primary antibody used was anti-PAX5 (SP34) Rabbit Monoclonal Primary Antibody ready to use from Ventana Medical Systems, Inc. 1910E. Innovation Park Drive (Tucson, Arizona 85755 USA). The universal kit used was ultraView Universal DAB Detection Kit.

A section of reactive lymphoid hyperplasia was used as a control according to the manufacturer recommendations. PAX5 nuclear expression level was classified depending on the intensity of PAX5 immunostaining. Scoring of the intensity of PAX5 immunostaining was done semi-quantitatively: $0=$ Negative; $1+=$ weak staining; and $2+=$ strong staining [13].

\section{Capturing of microscopic photos}

Microscopic photos were captured using a digital camera attached LEICA microscope model ICC50 HD.

\section{Statistical analysis}

Data were coded and entered using the Statistical Package for the Social Sciences version 26 (IBM Corp., Armonk, NY, USA). Data were summarized using mean, standard deviation, median, minimum and maximum in quantitative data, and using frequency (count) and relative frequency (percentage) for categorical data. Comparisons between quantitative variables were done using the non-parametric MannWhitney U-test [14]. For comparing categorical data, Chi-square $\left(\chi^{2}\right)$ test was performed. Exact test was used instead when the expected frequency is $<5$ [15]. $p<0.05$ was considered as statistically significant.

\section{Results}

This study included 60 cases of lymphoid neoplasms. Among the studied cases, $66.7 \%$ were mature B-cell lymphoma and $33.3 \%$ were classic Hodgkin lymphoma (CHL). Concerning the studied mature B-cell lymphoma, 5\% were small lymphocytic lymphoma, 15\% were mantle cell lymphoma, 15\% were follicular lymphoma, and $65 \%$ were diffuse large B-cell lymphoma (DLBCL). The age among the 
Table 1: Age, gender, and clinical presentation among the studied cases

\begin{tabular}{|c|c|c|c|c|c|c|}
\hline \multirow[t]{2}{*}{ Clinical Data } & \multirow[t]{2}{*}{ Small lymphocytic lymphoma } & \multicolumn{4}{|l|}{ Mature B-cell lymphoma } & \multirow{2}{*}{$\begin{array}{l}\text { Classic Hodgkin } \\
\text { lymphoma }\end{array}$} \\
\hline & & Mantle cell lymphoma & Follicular lymphoma & DLBCL & & \\
\hline \multicolumn{2}{|c|}{ Distribution of the studied cases } & 2 & 6 & 6 & 26 & 20 \\
\hline \multirow{5}{*}{ Age (year) } & Mean & 56.00 & 39.83 & 41.83 & 48.00 & 39.95 \\
\hline & SD & 1.41 & 6.27 & 22.17 & 16.62 & 17.38 \\
\hline & Median & 56.00 & 40.00 & 39.00 & 48.00 & 35.50 \\
\hline & Minimum & 55.00 & 32.00 & 17.00 & 24.00 & 18.00 \\
\hline & Maximum & 57.00 & 48.00 & 76.00 & 84.00 & 76.00 \\
\hline \multirow[t]{2}{*}{ Gender } & Male & 0 & 5 & 3 & 13 & 13 \\
\hline & Female & 2 & 1 & 3 & 13 & 7 \\
\hline \multirow[t]{3}{*}{ Clinical presentation } & Generalized lymphadenopathy & 1 & 2 & 1 & 3 & 3 \\
\hline & Localized lymphadenopathy & 1 & 4 & 4 & 13 & 16 \\
\hline & Extranodal lesion & 0 & 0 & 1 & 10 & 1 \\
\hline
\end{tabular}

DLBCL: Diffuse large B-cell lymphoma CHL: Classic Hodgkin lymphoma.

studied cases ranged from 17 to 84 years with a mean of $44.15 \pm 16.70$ years (Table 1 ). The studied cases showed male predominance in most cases. Localized lymphadenopathy was the most common clinical presentation among the studied cases.

All mature B-cell lymphoma cases were positive for CD20 and PAX5. All CHL cases were negative for CD20. Eighteen $\mathrm{CHL}$ cases were positive for PAX5. Two $\mathrm{CHL}$ cases were negative for PAX5. All positive CD20 cases (40) were positive for PAX5. Regarding the 20 cases negative for CD20 immunostaining, 18 cases were positive for PAX5 while two cases were negative for PAX5.

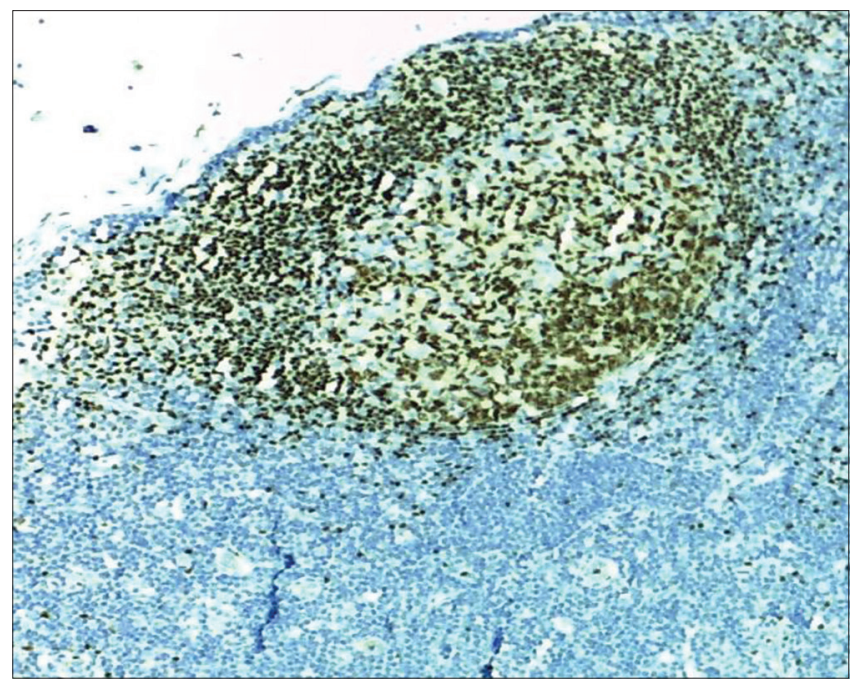

Figure 1: Reactive follicular hyperplasia (control) showing PAX5 nuclear staining primarily restricted to follicular regions, with strong nuclear staining present in mantle zone cells, less intense staining in follicle center cells, and negative staining in T-cell zone (immunoperoxidase $D A B \times 400$ )

All mature B-cell lymphoma cases were positive for PAX5. All mature B-cell lymphoma cases were negative for $\mathrm{CD} 30$. All $\mathrm{CHL}$ cases were positive for CD30. Eighteen CHL cases were positive for PAX5. Two CHL cases were negative for PAX5.

All cases of small lymphocytic lymphoma, mantle cell lymphoma, and 10 cases of DLBCL showed strong staining. All cases of follicular lymphoma and 18 cases of $\mathrm{CHL}$ showed weak staining. Two cases of $\mathrm{CHL}$ showed negative staining (Table 2 and Figure 2).

Correlation between diagnosis and CD20, CD30 showed a statistically significant correlation $(p<0.001)$, while correlation between diagnosis and PAX5 showed a non-statistically significant correlation $(p=0.107)$.

\section{Discussion}

Lymphoid neoplasms are clonal tumors of mature and immature B cells, T cells, or NK cells at various stages of differentiation which appear to recapitulate stages of normal B-cell or T-cell

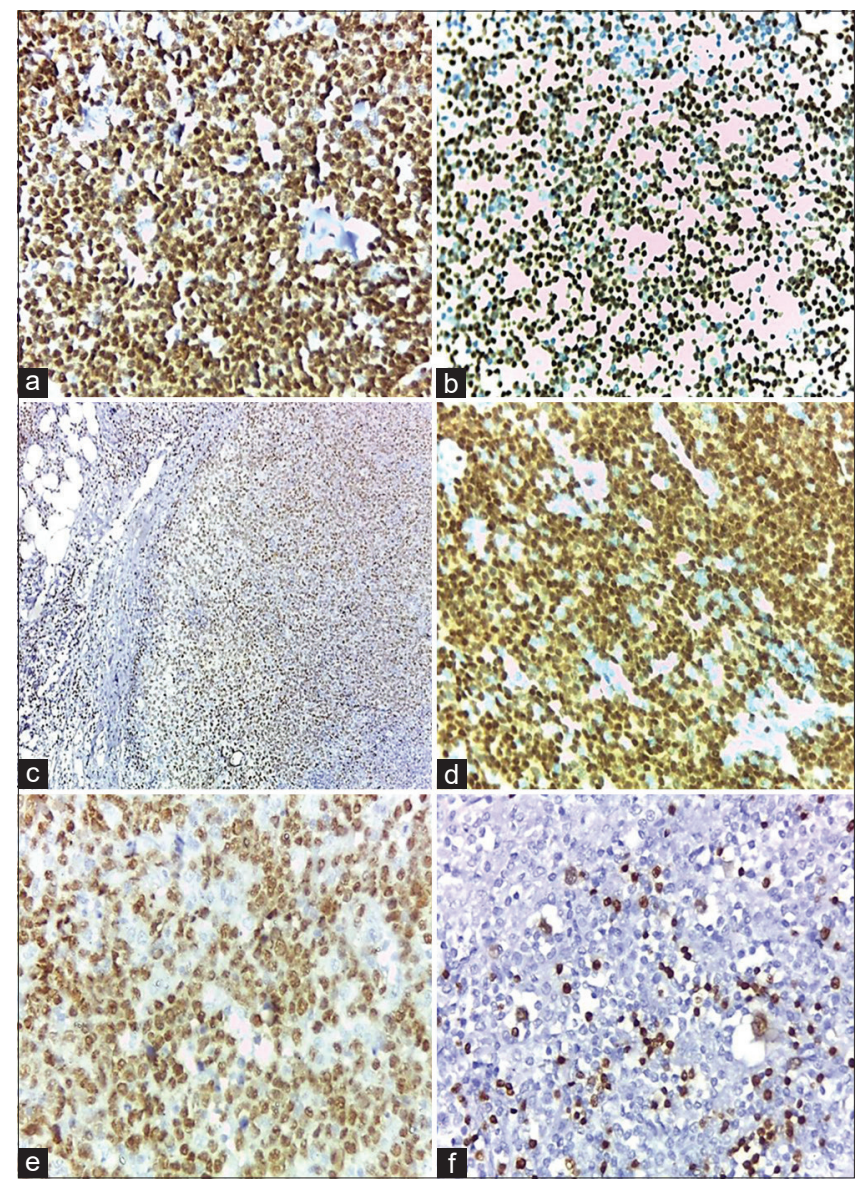

Figure 2: PAX5 immunostaining. (a) Small lymphocytic lymphoma showing strong PAX5 nuclear staining of neoplastic lymphoid cells; immunoperoxidase diaminobenzidine $(D A B) \times 400$. (b) Mantle cell lymphoma showing strong PAX5 nuclear staining of neoplastic lymphoid cells; immunoperoxidase $D A B \times 400$. (c) Follicular lymphoma showing weak $P A X 5$ nuclear staining of neoplastic lymphoid cells; immunoperoxidase $D A B \times 400$. (d) Diffuse large B-cell lymphoma showing strong PAX5 nuclear staining of neoplastic lymphoid cells, immunoperoxidase $D A B \times 400$. (e) Diffuse large B-cell lymphoma showing weak PAX5 nuclear staining of neoplastic lymphoid cells, immunoperoxidase DAB $\times$ 400. (f) Classic Hodgkin lymphoma, nodular sclerosis showing weak PAX5 nuclear staining of HRS neoplastic cells (arrow), compared with strong PAX5 nuclear staining in surrounding reactive $B$-cell (Immunoperoxidase DAB $\times 400$ ) 
differentiation; therefore, the current WHO classification of lymphoid neoplasms, which was used in the present study, classified lymphoid neoplasms into precursor lymphoid neoplasms, mature B-cell neoplasms, mature T- and NK-cell neoplasms, and Hodgkin lymphoma [1].

Diagnosing the type of lymphoma and subcategorizing them is challenging as most of them have an overlapping morphology. Immunohistochemistry is mandatory to establish the cell lineage and PAX5 is one such marker used in diagnosis of specific subtype of lymphoma [2].

PAX5 gene located on chromosome 9p13 is one of the paired box genes. It encodes for the transcription factor PAX5 also called BSAP which plays an important role in B-cell development [16].

The present study aimed at investigating PAX5 antigen expression in formalin-fixed, paraffin-embedded sections of 60 cases of lymphoid neoplasms and to study the utility of including PAX5 immunostaining in the immunohistochemical panel of lymphoma.

The studied 60 cases included 40 cases mature B-cell lymphomas and 20 cases CHLs. The studied mature B-cell neoplasms include two cases small lymphocytic lymphoma, six cases mantle cell lymphoma, six cases follicular lymphomas, and 26 cases DLBCLs. The age range of the studied cases at presentation was $17-84$ years, with mean age 44.15 years $( \pm 16.70)$ and median age 42 years. The studied cases showed male preponderance with female-to-male ratio 1:1.3.

The expression of PAX5 was detected as sharp nuclear staining. No definite cytoplasmic or membranous staining was noted which makes the assessment of immunostaining easy.

PAX5 expression in reactive lymph node (which was used as a positive control in this study) was found only in the nuclei of B-lymphocytes (B-cell zone). No expression of PAX5 was seen in T-cell (T-cell zone), plasma cells, or extra-follicular large transformed B-cells. The intensity of PAX5 expression in B-cell zone is variable being more intense in mantle cell zone than in germinal center B-cells, whereas the marginal zone showed weak staining (Figure 1).

The pattern and intensity of PAX5 expression observed in reactive lymph node in this study is similar to that observed by Krenacs et al., 1998 [17], who reported that the strong PAX5 expression in mantle zone maybe due to the presence of important PAX5 target genes in mantle B-cells. However, the less intense PAX5 expression in germinal center B-cells is curious because of the important role of PAX5 in class switch recombination. The absence of PAX5 expression in plasma cells is due to inhibition of PAX5 expression by the B-lymphocyte-induced maturation protein1 to terminate the germinal center program and initiate postgerminal center differentiation of selected centrocytes into plasma cells or memory B-cells.
Table 2: Expression of CD3, CD20, CD30, and PAX5 among the studied cases

\begin{tabular}{|c|c|c|c|c|c|c|}
\hline \multirow[t]{2}{*}{ Diagnosis } & \multirow[t]{2}{*}{ CD 3} & \multirow[t]{2}{*}{ CD20 } & \multirow[t]{2}{*}{ CD30 } & \multicolumn{3}{|c|}{ PAX-5 expression } \\
\hline & & & & Negative & Weak & Strong \\
\hline $\begin{array}{l}\text { Small lymphocytic } \\
\text { lymphoma }\end{array}$ & Negative & Positive & Negative & & & 2 \\
\hline $\begin{array}{l}\text { Mantle cell } \\
\text { lymphoma }\end{array}$ & Negative & Positive & Negative & & & 6 \\
\hline $\begin{array}{l}\text { Follicular } \\
\text { lymphoma }\end{array}$ & Negative & Positive & Negative & & 6 & \\
\hline DLBCL & Negative & Positive & Negative & & 16 & 10 \\
\hline $\mathrm{CHL}$ & Negative & Negative & Positive & 2 & 18 & \\
\hline
\end{tabular}

In the present study, PAX5 immunostaining was positive in $96.7 \%$ of the studied cases and negative in $3.3 \%$ of the studied cases. All $100 \%$ of studied mature B-cell lymphomas were positive for PAX5 immunostaining, however, the intensity of PAX5 immunostaining is variable among the different studied types of mature B-cell lymphomas. Mantle cell lymphoma showed strong PAX5 immunostaining because mantle cell lymphomas are derived from the mantle zone B cells which normally showed strong PAX 5 immunostaining. The studied small lymphocytic lymphoma cases also showed strong PAX5 immunostaining which may be due to their origin from an antigen-experienced mature CD5 positive B cell. All follicular lymphoma cases also showed strong PAX5 immunostaining in contrast to the weak PAX5 immunostaining in reactive germinal center $\mathrm{B}$ cells. This observation suggests that PAX5 may be expressed at high level in follicular lymphomas. As regard the DLBCL cases, 16 cases showed weak PAX5 immunostaining, and 10 cases showed strong PAX5 immunostaining. This variability in the intensity of PAX5 immunostaining may be due to the clinical, pathological, and molecular heterogeneity of DLBCLs.

Krenacs et al., 1998 [17], studied PAX5 expression in 102 cases of mature B-cell neoplasms and observed that $81 \%$ of these cases were positive for PAX5 immunostaining, whereas $19 \%$ of these cases were negative for PAX5 immunostaining. All of the studied small lymphocytic lymphoma, mantle cell lymphoma, and follicular lymphomas were positive and only $79 \%$ of DLBCL were positive. They mentioned that the PAX5- negative DLBCL cases might be derived from post-follicular transformed $B$ cells representing the transition between mature $B$ cells to plasma cells. The remaining PAX5-negative cases were plasma cell neoplasms derived from plasma cells in which PAX5 expression is suppressed. As regard the intensity of PAX5 immunostaining in their study, all mantle cell lymphoma and only half of the DLBCL showed strong PAX5 immunostaining, whereas most of small lymphocytic and follicular lymphomas showed less intense staining.

In the study performed by Foss et al., 1999 [18], all mature B-cell neoplasms except plasma cell neoplasms were positive for PAX5 immunostaining. This is similar to the results of the present study but they did not comment on the intensity of the staining in the studied types. All mature B-cell neoplasms except plasma cell neoplasms were positive for PAX5 
immunostaining. This is similar to the results of the present study but they did not comment on the intensity of the staining in the studied types.

Torlakovic et al., 2002 [13], found that among the studied cases of mature B-cell lymphomas, all cases were positive for PAX5 immunostaining except plasma cell neoplasms and four cases of DLBCL. All the four PAX5-negative DLBCL expressed cytoplasmic immunoglobulin and were negative for CD20 and CD45, consistent with terminal B-cell differentiation, also two of these cases expressed CD138. PAX5 immunostaining was strong in all positive cases of mature B-cell neoplasms except five cases of DLBCL and two cases of splenic marginal zone lymphoma which showed weak expression.

Desouki et al., 2010 [19], found that all their studied cases of mature B-cell lymphoma, represented by small lymphocytic lymphoma, and DLBCL were positive for PAX5 immunostaining, and all their studied small lymphocytic lymphoma cases showed diffuse strong nuclear staining. These results are similar to the present study. However, in contrast to the present study, all their studied DLBCL cases showed strong diffuse nuclear staining, but they did not mention the type of the studied DLBCL which may be the cause of the variability in the intensity of staining between their study and the present study. Desouki et al., 2010 [19], also found that all the studied T-cell lymphoma cases were negative for PAX5 immunostaining. The results of Desouki et al., 2010 [19], highlight the beneficial role of including PAX5 in the immunohistochemical panel of lymphoid neoplasms, because as PAX5 is specific for B-cell lineage so positivity for PAX5 not only confirms the B-cell origin but also excludes other origins for any given lymphoid neoplasm.

Madanagopaal et al., 2016 [20], studied PAX5 expression on 14 cases of B-cell lymphomas and found that 12 cases showed strong PAX5 immunostaining and 2 cases were negative. However, they do not mention the type of PAX5 negative B-cell lymphoma present in their study.

In this study, $90 \%$ of the studied $\mathrm{CHL}$ cases were positive for PAX5 immunostaining. However, the immunostaining of Hodgkin and Reed/Sternberg (HRS) cells is weaker than that of surrounding reactive $B$ cells, a feature that makes the PAX5-positive HRS cells easily identifiable. This weak PAX5 immunostaining of HRS cells is attributed to the altered B-cell program in HRS cells which make most HRS cells CD20 negative. The positivity of HRS cells provides evidence that HRS cells are of B-cell origin. No association was observed between PAX5 expression and the histologic subtype of $\mathrm{CHL}$.

Krenacs et al., 1998 [17], in their study found that $36 \%$ of studied CHLs were PAX5 positive. Although this result is lower than the present study, yet the PAX5positive HRS cells show weak nuclear or nucleolar staining similar to the present study.
Foss et al., 1999 [18], in their study found that $90 \%$ of studied $\mathrm{CHL}$ cases were PAX5 positive which is similar to the results of the present study. However, the staining intensity was very variable ranging from weak to moderate to rarely strong compared with surrounding reactive lymphocytes. Furthermore, they observed that there was no association between PAX5 positivity and histological subtype of CHLs.

Torlakovic et al., 2002 [13], found that $3 \%$ of studied $\mathrm{CHL}$ cases were negative for PAX5 immunostaining, and $97 \%$ were positive for PAX5 immunostaining. PAX5 staining was weak in $92 \%$ of cases and strong in $5 \%$ of positive cases.

Desouki et al., 2010 [19], observed that $87 \%$ of their studied $\mathrm{CHL}$ were positive for PAX5 immunostaining, and there was no association between PAX5 immunostaining and the histologic subtype of $\mathrm{CHL}$. Although these results are nearly similar to the present the present, yet they did not comment on the intensity of PAX5 immunostaining in the studied cases of $\mathrm{CHL}$.

Madanagopaal et al., 2016 [20], in their study observed that $71 \%$ of the studied cases of $\mathrm{CHL}$ were PAX5 positive and $29 \%$ of these cases were PAX5 negative. Furthermore, all their studied cases showed strong nuclear staining which is not observed in the present study as well as in the studies of Krenacs et al., 1998, Foss et al., 1999, and Torlakovic et al., 2002.

Most histological subtypes of the studied CHLs are characterized by paucity of neoplastic HRS cells, however, some subtypes of $\mathrm{CHL}$, especially lymphocyte depleted subtype, are rich in neoplastic HRS cells. These cases may morphologically resemble anaplastic large cell lymphomas, a T-cell neoplasm. PAX5 positivity in HRS cells facilitates the identification of these $\mathrm{CHL}$ subtypes.

\section{Conclusion}

From this study the following were concluded:

PAX5 in the immunohistochemical panel of lymphoma helps to establish B cell lineage and increases the diagnostic and treatment accuracy.

PAX5 immunostaining intensity varies among normal B-cell subsets and among subtype of B-cell lymphoma, with the strongest intensity detected in normal and neoplastic mantle cells. PAX5 immunostaining provides an evidence for the B-cell origin of HRS cells of classic Hodgkin lymphoma.

PAX5 expression being a sharp nuclear staining with no definite cytoplasmic or membranous staining makes the assessment of PAX5 immunostaining more clear \& easy. 
However being a nuclear antigen it is altered with poor tissue preservation.

Further molecular studies are recommended in order to explain the variability in the intensity of PAX5 immunostaining among normal B-cell subsets among subtypes of B-cell lymphoma \& Hodgkin lymphoma. Further prospective studies are recommended in order to identify prognostic significance of PAX5 immunostaining among subtypes of B-cell lymphoma and Hodgkin lymphoma. Further molecular studies are recommended in order to identify the nature and origin of PAX5 negative HRS cells..

\section{References}

1. Jaffe ES, Campo E, Harris NL, Pileri SA, Stein H, Swerdlow $\mathrm{SH}$. Introduction and overview of the classification of lymphoid neoplasms. In: Swerdlow SH, Campo E, Harris NL, Jaffe ES, Pileri SA, Stein H, et al, editors. WHO Classification of Tumours of Haematopoietic and Lymphond Tissues. $4^{\text {th }}$ ed. Lyon, France: IARC Press; 2017. p. 190-8. https://doi.org/10.1182/ blood-2011-01-293050

2. Dong HY, Browne P, Liu Z, Garagi M. PAX5 is invariably expressed in B-cell lymphoma without plasma cell differentiation. Histopathology. 2008;53(3):278-87. https://doi. org/10.1111/j.1365-2559.2008.03091.x

PMid:18643853

3. Inlay MA, Bhattacharya D, Sahoo D, Serwold T, Seita J, Karsunky $\mathrm{H}$, et al. Ly6d marks the earliest stage of B-cell specification and identifies the break point between B-cell and T cell development. Genes Dev. 2009;23:2376-81. https://doi. org/10.1101/gad.1836009

4. Nutt SL, Kee BL. The transcriptional regulation of $B$ cell lineage commitment. Immunity. 2007;26(6):715-25. https://doi. org/10.1016/j.immuni.2007.05.010

PMid:17582344

5. Lin YC, Jhunjhunwala S, Benner C, Heinz S, Welinder E, Mansson $\mathrm{R}$, et al. A global network of transcription factors, involving E2A, EBF1, and Foxol, that orchestrates B cell fate. Nat Immunol. 2010;11(7):635-43. https://doi.org/10.1038/ni.1891 PMid:20543837

6. Medvedovic J, Ebert A, Tagoh H, Busslinger M. PAX5: A master regulator of $B$ cell development and leukemogenesis. Adv Immunol. 2011;111:179-206. https://doi.org/10.1016/ b978-0-12-385991-4.00005-2

PMid:21970955

7. Schebesta A, Mc Manus S, Salvagiotto G, Delogu A, Busslinger GA, Busslinger $M$. Transcription factor PAX5 activates the chromatin of key genes involved in B cell signaling, adhesion, migration, and immune function. Immunity. 2007;27(1):49-63. https://doi.org/10.1016/j.immuni.2007.05.019 PMid: 17658281

8. McManus S, Ebert A, Salvagiotto G, Medvedovic J, Sun Q, Tamir J, et al. The Transcription factor PAX5 regulates its target genes by recruiting chromatin-modifying proteins in committed
B cell. EMBO J. 2011;30(12):2388-404. https://doi.org/10.1038/ emboj.2011.140

PMid:21552207

9. Johnson K, Pflugh DL, Hesslein DG, Link L, Bothwell AL. Thomas-Tikhonenko A, et al. B cell-specific loss of histone 3 lysine 9 methylation in the VH Locus depends on PAX5. Nat Immunol. 2004;5(8):853-61. https://doi.org/10.1038/ni1099 PMid: 15258579

10. Fuxa M, Shok J, Souabni A, Salvagiotto G, Roldan E, Busslinger M. PAX5 induces V-to DJ rearrangements and locus contraction of the immunoglobulin heavy-chain gene. Genes Dev. 2004;18(4):411-22. https://doi.org/10.1101/gad.291504 PMid: 15004008

11. Rozanski $\mathrm{CH}$, Arens R, Carlson LM, Nair J, Boise LH, ChananKhan AA, et al. Sustained antibody responses depend on CD28 function in bone marrow-resident plasma cells. J Exp Med. 2011;208(7):1435-46. https://doi.org/10.1084/jem.20110040 PMid:21690252

12. Swerdlow SH, Campo E, Harris NL, Jaffe ES, Pileri SA. WHO Classification of Tumours of Hematopoietic and Lymphoid Tissues. $4^{\text {th }}$ ed. Lyon, France: IARC Press; 2017.

13. Torlakovic E, Torlakovic G, Nguyen PL, Brunning RD, Delabie $\mathrm{J}$. The value of anti-PAX-5 immunostaining in routinely fixed and paraffin-embedded sections: A novel pan pre-Band B-cell marker. Am J Surg Pathol. 2002;26(10):1343-50. https://doi. org/10.1097/00000478-200210000-00011 PMid:12360049

14. Chan YH. Biostatistics 102: Quantitative data-parametric and non-parametric tests. Singapore Med J. 2003a;44(8):391-6.

PMid:14700417.

15. Chan YH. Biostatistics 103: Qualitative data-tests of independence. Singapore Med J. 2003b;44(10):498-503. PMid:15024452

16. Barberis A, Widenhorn K, Vitelli L, Busslinger M. Anovel B-cell lineage-specific transcription factor present at early but not late stages of differentiation. Genes Dev. 1990;4(5):849-59. https:// doi.org/10.1101/gad.4.5.849

PMid:2116362

17. Krenacs L, Himmelmann AW, Quintanilla-Martinez L, Fest $T$, Riva A, Wellmann A, et al. Transcription factor B-cell specific activator protein (BSAP) is differentially expressed in B-cells and in subsets of B-cell lymphomas. Blood. 1998;92(4):1308-16. https://doi.org/10.1182/blood.v92.4.1308.416k32_1308_1316 PMid:9694719.

18. Foss HD, Reusch R, Demel G, et al. Frequent expression of the B-cell-specific activator protein in Reed-Sternberg cells of classical Hodgkin's disease provides further evidence of its B-cell origin. Blood. 1999;94(9):3108-13. https://doi. org/10.1182/blood.v94.9.3108.421a21_3108_3113 PMid:10556196

19. Desouki MM, Past GR, cherry D, and Lazerchick J. PAX5: A valuable immunohistochemical marker in the differential diagnosis of lymphoid neoplasms. Clin Med Res. 2010;8(2):848. https://doi.org/10.3121/cmr.2010.891 PMid:20660931

20. Madanagopaal LR, Subashchandrabose $P$, Sivanandam $S$. Analysis of PAX5 expression of Hodgkin's and non-Hodgkin's lymphomas in comparison with routine panel. Arch Cyto Histopathol Res. 2016;1(1):4-13. 